\title{
ANALYSIS OF LONG-CIRCUIT TYPE CAISSONS FOR ATTENUATION OF LONG-PERIOD WAVES
}

\author{
Jose A. GONZALEZ-ESCRIVA ${ }^{1}$, Jorge MOLINES ${ }^{1}$, \\ Josep R. MEDINA ${ }^{1}$ and M. Esther GÓMEZ-MARTÍN
}

\begin{abstract}
An experimental methodology for modelling resonant response simulation of dissipative structures and the procedure for its consequent analysis is presented. Results are described from large scale experiments of Jarlan-type caissons made of dissipative long-circuits for minimizing long-period oscillations in port basins.
\end{abstract}

Keywords: harbor resonance; long-period oscillations; Jarlan-type caisson; ARJ-R structures; dissipative longcircuit caisson

\section{INTRODUCTION}

\section{Long-period wave induced problems in port and harbor basins}

Sheltered water areas inside ports and harbors can only be exposed to external forcing through the entrances. Breakwaters provide convenient shelter for short-period waves $(1<T[s]<30)$, thus limiting the amount of energy entering the harbor. This wave energy in the port basins may be amplified, due to the wave reflection, which may disturb port operations. Anti-reflective Jarlan-type (ARJ) structures (see Jarlan, 1961) have been proposed in the literature, along with other structures, to alleviate wave disturbance within port basins. The ARJ anti-reflective mechanism is based on the destructive interference of waves. An anti-reflective zone width, $B$, must be almost a quarter of the wavelength $(B \approx L / 4)$ for maximum efficiency.

Longer waves $(L>>4 B)$ easily enter the port-sheltered area where resonance phenomena could magnify their energy under certain conditions. Port resonance is the phenomenon of energy amplification that takes place in a harbor or port basin if the incident waves have frequencies close to those of the natural oscillation of the mass of water in the port basin, typically in the range $30<T[s]<300$. This infragravity (IG) long wave energy is much more difficult to dissipate, being frequently reported as causing trouble in cargo handling areas of many ports (see Rabinovich, 2009), even leading to breakages of mooring lines and other relevant damage (see Thotagamuwage and Pattiaratchi, 2014). The situation can even become worse if the coupling between these forced oscillations and the water mass in the basin is extended to the mooring systems and/or the ship itself producing other types of resonance.

If a port is exposed to long-period resonant oscillations, an accurate estimation of the consequent yearly downtime in port operation appears to be of major importance. However, despite the fact that the availability of wave records are expanding geographically, standard instrumentation for wave measurement does not record long time enough to measure long waves. Moreover, the relationship between short-period waves and long-period waves due to remaining uncertainties in the long-period wave generation mechanisms it is still not well known. Therefore, because of this lack of measurements and due to uncertainties in the generation mechanisms of long-period waves, probability of occurrence for long-period waves and consequently port service downtime cannot be accurately estimated.

The aforementioned uncertainties that hinder the estimation of the probability of occurrence of long-period waves in a site, mean that the port designer must consider the natural oscillation modes of the port/basin (first and second natural modes typically) and the amplification factor to evaluate the associated problems to the port operation and safety conditions. Standard design for a new port typically includes numerical modeling of the port geometry and bathymetry under short and longwaves action. The design must avoid the amplification of locally existing wave periods which probability of occurrence are unknown for the long-period waves. Additionally, even if resonance occurs, an accurate estimation of the amplification factor leading to higher oscillation heights and more intense currents is difficult to obtain given the complexity of the existing dissipative mechanisms (bottom laminar boundary friction, wall laminar boundary friction, surface laminar boundary friction, dry friction from meniscus action or residual surface tension dissipation). Physical scale tests are

\footnotetext{
${ }^{1}$ Laboratory of Ports and Coasts, Universitat Politècnica de València, $C^{\circ}$ de Vera s/n, Valencia, 46022, Spain
} 
required to determine the dissipative features for both efficiency analysis and calibration of the numerical models.

These dissipative mechanisms can be used in the development of new ad-hoc dissipative elements in order to minimize the energy amplification factor produced by port resonance, thus increasing the port service hours per year. Besides, the complexity of these dissipative mechanisms require specific physical scale modelling to estimate the dissipative effectivity of such structures aside from other existing dissipative mechanisms in the basin.

This paper will focus on the analysis of a dissipative element named Anti-Reflective Jarlan-type structure for Resonance attenuation (ARJ-R) able to reduce resonant oscillations in port or harbor basins. A short summary of the physical model tests and the particular experimental Resonant Response Methodology (RRS) used for estimating the dissipative features of long-circuit ARJ-R caissons is also described. Finally, the results of the analysis of two long-circuit ARJ-R caissons to attenuate resonance oscillations are included using a design diagram.

\section{DISSIPATIVE MECHANISMS TO ATTENUATE LONG-PERIOD OSCILLATIONS IN BASINS}

Inside the port/basin, neither transmission nor overtopping is supposed to take place, thus attenuation of wave energy is directly related to the $C_{r}$. The objective is to minimize $C_{r}$, by means of a single or a combination of dissipative mechanisms. Low-frequency wave energy can be reduced by friction and turbulence dissipative mechanisms; however, large dissipative structures that cause friction, or complex geometries that produce turbulence are unsuitable for easy maneuvering and berthing (see Gonzalez-Escriva, 2017).

Even though ARJ structures could combine dissipative mechanisms, the main one is based on the "destructive interference of waves" leading up to a phase lag between incident and reflected waves of $\pi$ with a maximum dissipative efficiency when the relative width of the dissipative structure is about a quarter of the wave length. This characteristic wave destructive interference mechanism of ARJ structures may be used for long-period waves $(T[s]>30 \mathrm{~s})$. In this case, a space wider than the standard width of a pre-cast caisson would be required for the anti-reflective zone.
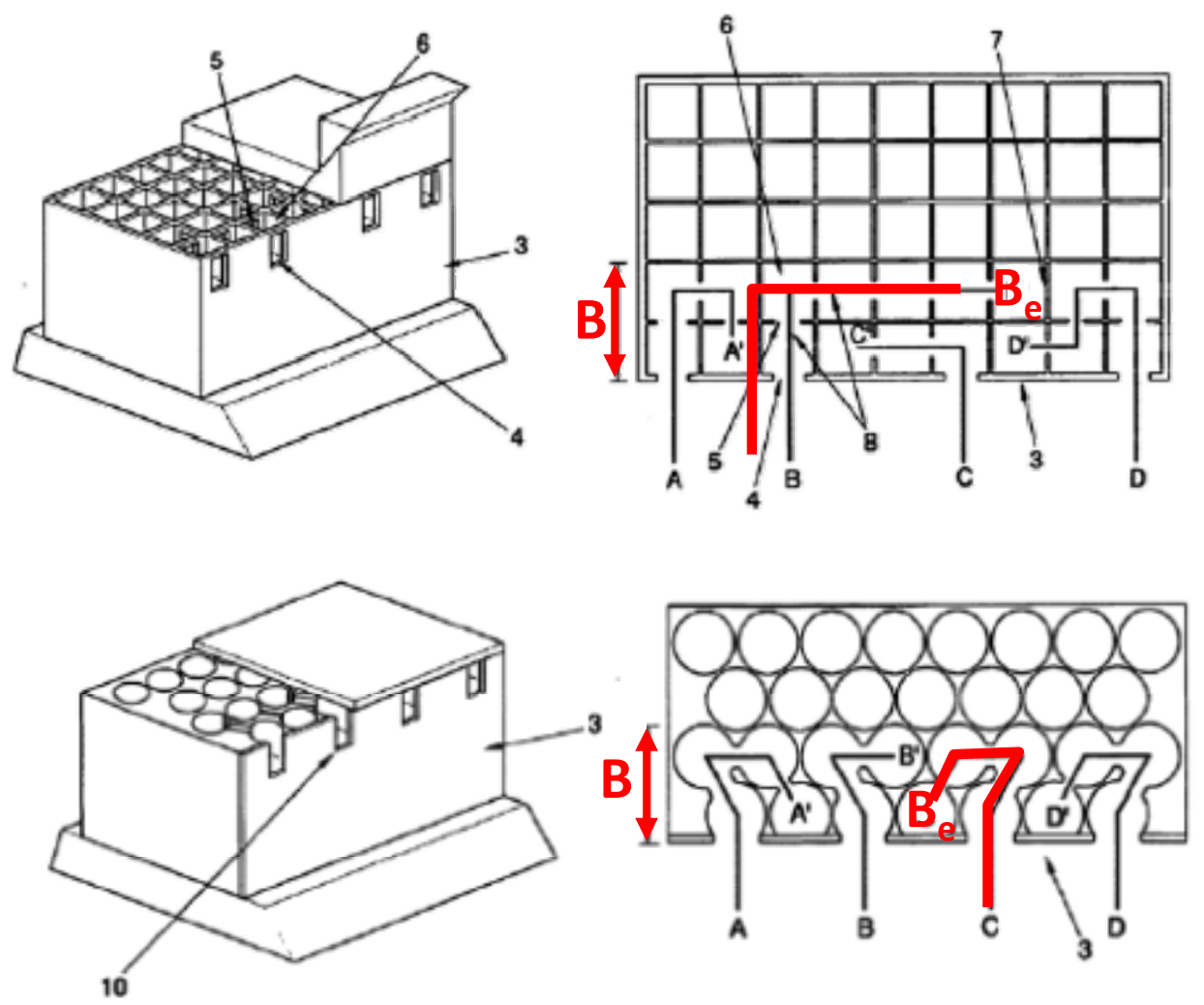

Figure 1. Examples of two long-circuit caisson: long-circuit pathways longer than the width of the antireflective zone $\left(B_{e}>B\right)$. 


\section{ARJ caisson with dissipative long-circuits (ARJ-R)}

To overcome this technical and economic problem, the design of an ARJ vertical structure can be based on the multi-cell circuit concept proposed by Medina et al. (2016). A circuit is defined as the space forming the inner pathway that is used by the water flow induced by waves within the caisson. The use of the long-circuit concept could provide an effective width for the antireflective zone, $B$, equal to the length of the circuit, $B_{e}$. Figure 1 shows two types of long-circuit caissons where pathways are larger than the width of the antireflective zone. Long-circuit ARJ-R caissons are a possible solution for the attenuation of long-period oscillations produced by IG waves in ports and harbor basins. The concept is based in the creation of water pathways inside the caisson where the waves and the water flow are forced to run. Those pathways could be larger than the width of the caisson, thus extending the effectivity of the ARJ dissipative mechanisms to the range of IG waves. In addition, dissipative long-circuits of different lengths can be built-in the caisson to provide technical solutions to different wave/oscillation conditions being possible to enhance their effectivity for a wide range of situations.

ARJ-R long-circuit caissons may be effective in reducing port resonance (see Gonzalez-Escriva and Medina, 2012) without enlarging the width of the structure, compatible with ship maneuvering and berthing, offering a practical solution from the constructive point of view, as well as being economically feasible (see Martinez et al, 2010).

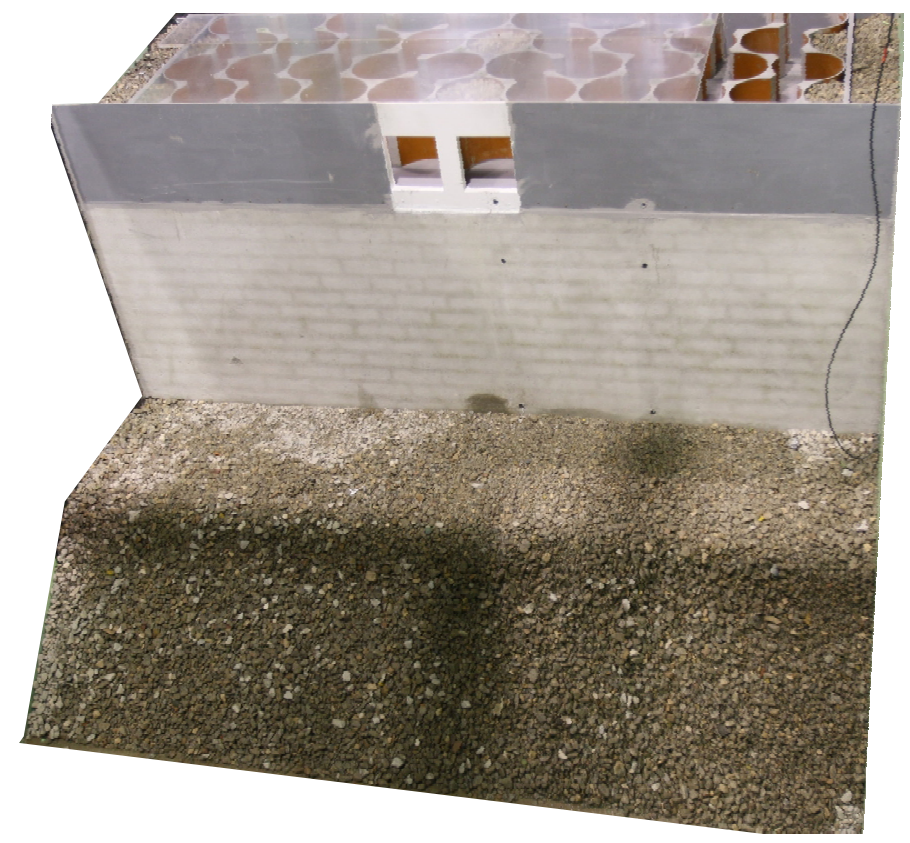

Figure 2. ARJ-R caisson with dissipative long-circuits of connected circular cells.

Given the complexity of the structure geometry and the processes involved (destructive interference of waves with contribution of inevitable friction and turbulence), physical small-scale testing is necessary to estimate the antireflective efficiency of the dissipative elements and for calibration of numerical models.

\section{LARGE SCALE PHYSICAL TESTING OF ARJ-R LONG-CIRCUIT CAISSONS}

Large-scale models (1/11:6 scale) of two ARJ-R caissons and an additional impervious caissontype vertical breakwater were tested in 2D physical experiments in the large wave flume $(90 \times 4.6 \times 3.6$ $\mathrm{m})$ at the CEDEX (Spanish Centre for Public Works Studies and Experimentation). Fig. 2 reproduces one of the two ARJ-R caissons tested, with dissipative long-circuits of connected circular cells.

A new experimental RRS methodology was used to overcome the drawbacks of conventional methodologies when testing long-period waves. This particular methodology (see Gonzalez-Escriva et al., 2018) is based on energy accumulation and subsequent decay, which simulates the resonant response of a closed narrow rectangular basin. Fig. 3 shows the layout of the wave flume used for the physical experimentation where both the wave paddle and the model must be watertight in order to prevent losses in the water volume (also the bottom has to be impervious too). Tests were carried out in 
resonance conditions for wave periods of 45 and $90 \mathrm{~s}$ at prototype scale corresponding to the first and second natural modes of oscillation of the water mass in the wave flume.

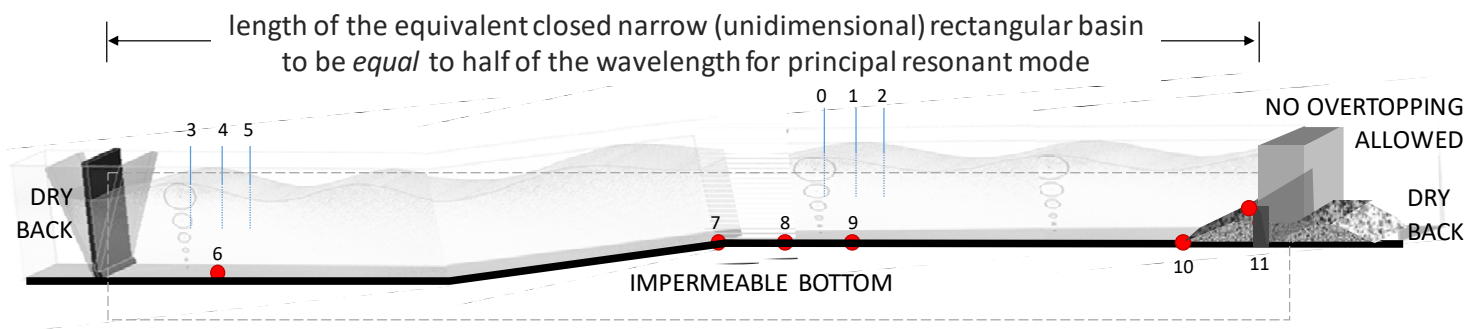

Figure 3. Cross-section of the wave flume for RRS testing of ARJ-R structures with long-period oscillations

A conventional impermeable structure was tested first to evaluate the dissipative efficiency of the wave flume without any antireflective structure, and then the different ARJ-R structures were tested to comparatively evaluate their efficiency. Two series of tests were carried out on an ARJ-R caisson (36.95 m x $15.7 \mathrm{~m} \mathrm{x} 17 \mathrm{~m}$ at prototype scale) based on either circular or rectangular cells that were connected to form long circuits with openings on the frontal face of the caisson (Figs. 4 and 5). Caissons with 2, 3 and 4 long dissipative circuits with both circular and rectangular cells were tested.

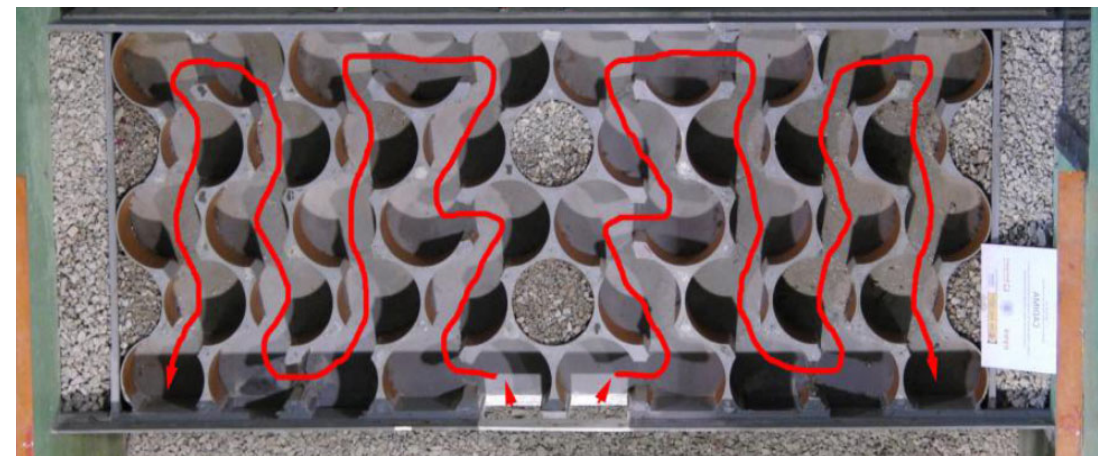

Figure 4. Plan view of ARJ-R caisson with two circuits of 23 circular cells

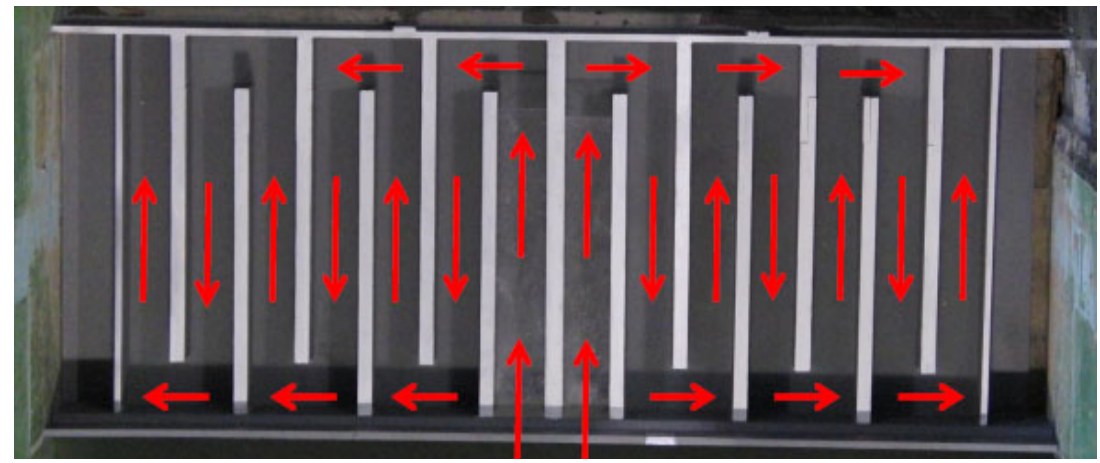

Figure 5. Plan view of ARJ-R caisson with two circuits of $\mathbf{4 2}$ rectangular cells

\section{ANALYSIS OF LONG-CIRCUIT CAISSONS FOR ATTENUATION OF LONG-PERIOD WAVES}

A particular approach to analyze the antireflective performance of maritime structures subject to long-period waves is proposed to compare the long-circuit caissons tested with circular and rectangular cells (see Gonzalez-Escriva, 2017). This analysis is complementary to the RSS experimental methodology used for the physical model tests of the ARJ-R caissons. 
According to the 2-phase RRS experimental methodology, oscillations at the natural frequency of the rectangular wave flume are generated using a linear sinusoidal scheme without active absorption. Together with the sealed volume of water, the first phase of accumulation of energy is produced in the flume/basin. The decay phase starts when the wave paddle stops; there is no external energy input and the dissipative mechanisms take control of the wave-flume system. In the decay phase water oscillates freely at the closest natural frequencies of the basin decreasing its amplitude in time (Fig 6).

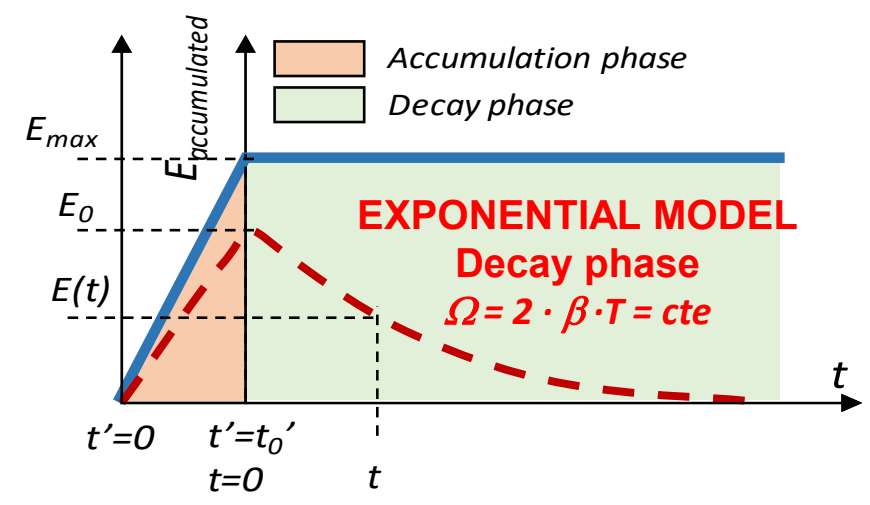

Figure 6. Energy in the wave flume: without energy dissipation (blue line) and with energy dissipation (red broken line).

The parameter to characterize the amount of dissipated energy is the decay coefficient (see Keulegan, 1959)

$$
\frac{H(t)}{H(t=0)}=\mathrm{e}^{-\beta \cdot \mathrm{t}}
$$

where $t$ is the time since the wave generation stops, $E(t)$ is the height of the oscillation at a time $t$ in the decay phase measured near the structure to be tested, and $\beta$ is the time-dependent decay rate of the system.

A typical record of the vertical water displacement at the position of a wave gauge near the model highlights the difference in the dissipative efficiency of an ARJ-R caisson compared to a vertical fullyreflective caisson, where the oscillations persist for a longer period of time (Fig 7).

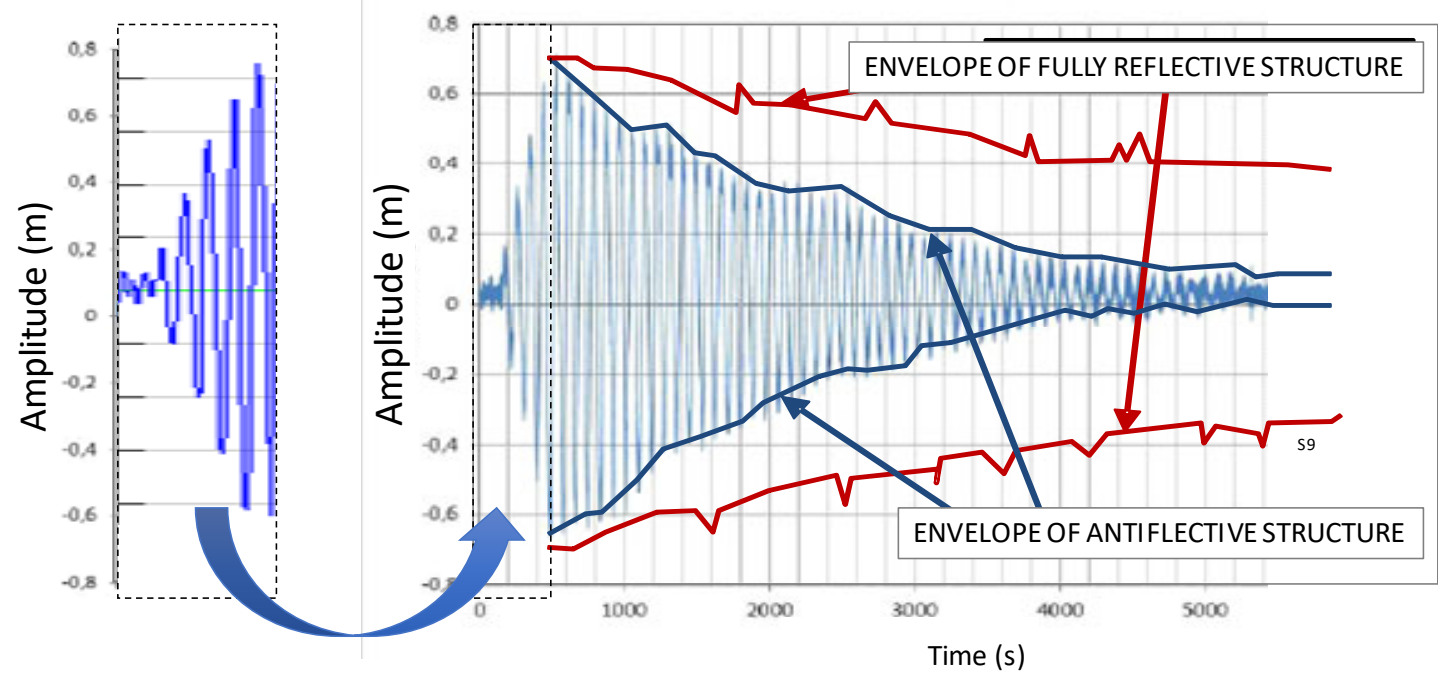

Figure 7. Oscillation amplitude in a typical RSS experiment during the accumulated and decay phase. 
The procedure to obtain the decay coefficient, $\beta$ consists of three steps:

1. Energy in the system is estimated through a smoothed time series of the square of the recorded vertical displacement. Barlett (triangular) windows or SIWEH are used for smoothing the original time series.

2. Homogenization of the energy time series is carried out when the time-origin is set to the start of the decay phase, and the maximum energy at decay phase starts with a normalized energy equal to the unit.

3. Decay coefficient is estimated for the best fit to the resulting time-energy in the decay phase of the experiment.

Table 1 summarizes the antireflective features for all the sections tested. Relative exponential coefficients, $\beta_{T} / \beta_{R E F}$, indicate the time the impermeable section needs to reduce the energy to a certain level compared to the long-circuit caissons.

\begin{tabular}{|c|c|c|c|c|c|}
\hline \multirow{2}{*}{$\begin{array}{l}\text { Long-circuit } \\
\text { caisson tested }\end{array}$} & \multirow{2}{*}{ Type of cells } & \multirow{2}{*}{ No. of circuits } & \multirow{2}{*}{$\begin{array}{l}\text { Circuit length } \\
\text { caisson width }\end{array}$} & $\mathrm{T}=45 \mathrm{~s}$ & $\mathrm{~T}=90 \mathrm{~s}$ \\
\hline & & & & $\beta_{T} / \beta_{\text {REF }}$ & $\beta_{T} / \beta_{R E F}$ \\
\hline \multicolumn{2}{|c|}{ Caisson impermeable } & 0 & 0 & 1.00 & 1.00 \\
\hline ARJ-R Cl1 & \multirow{3}{*}{ circular } & 2 & 4 & 1.88 & 3.03 \\
\hline ARJ-R Cl2 & & 4 & 2 and 1 & 4.44 & 3.94 \\
\hline ARJ-R CI3 & & 6 & 2 and 1 & 4.68 & 2.88 \\
\hline ARJ-R RE1 & \multirow{3}{*}{ rectangular } & 2 & 7 & 1.96 & 4.76 \\
\hline ARJ-R RE2 & & 4 & 4 and 3 & 4.23 & 3.92 \\
\hline ARJ-R RE3 & & 6 & 3 and 2 & 5.39 & 2.37 \\
\hline
\end{tabular}

The reflection coefficient, $C_{r}$, can be defined for a time equal to one complete oscillation cycle, $T$ :

$$
\boldsymbol{C}_{\boldsymbol{r}}=\frac{H_{\text {ref }}}{H_{\text {inc }}}=\frac{H(t+T)}{H(t)}=e^{-\beta \cdot T}
$$

Moreover, every individual dissipative effect can be estimated using the former exponential model, then the reflection coefficient, $C_{r}$, of the stand-alone ARJ-R structure can also be determined. The process for reducing the analysis to the ARJ-R circuits without including any other dissipative effects is made in two steps:

1. First, to eliminate the dissipative effect of the walls-bottom and internal fluid viscosity, the decay coefficient of the impermeable vertical fully-reflective caisson (tested as a reference) is subtracted from the decay coefficient of the ARJ-R caisson.

2. Secondly, the resulting decay coefficient of the ARJ-R caisson is divided by the opening ratio (which is the portion of the cumulative width of the frontal windows in the caisson related to the total width. To this end, the stand-alone efficiency of the circuits that define the ARJ-R caisson can be estimated.

Once the analysis of the experimental results has been reduced to the circuit level (c subscript refers to circuit level), the typical design diagram $\left(C_{r, c}\right.$ as a function of the relative width, $\left.B_{c} / L_{c}\right)$ can be obtained as is shown in Fig. 8. It is shown that the long-circuits made of circular cells appears to be more effective than the long circuits made of rectangular cells.

In other words, to obtain a $C_{r}$ of 0.6 (approximately), a long-circuit made of circular cells may be shorter for a certain wave length. As a result, more circuits can be included in the caisson providing a lower $C_{r}$ for the caisson and then a higher dissipative efficiency.

The dissipative effect of a long-circuit is due to a combination of friction, turbulence and destructive wave interference. Long-circuits with rectangular cells mainly dissipate by friction and wave interference while turbulence is also important in long-circuits made of circular cells. If the final part of the circular cell circuit is too long, the dissipative mechanisms are not effective in the complete circuit length; for a given period of the water oscillation, the optimum circular cell circuit is shorter than for the rectangular one. As a result, ARJ-R caissons with circuits made of circular cells whose length has been optimized may have more circuits added. Long-circuit caissons made of circular cells are very effective in attenuating long-period oscillations in port basins. 


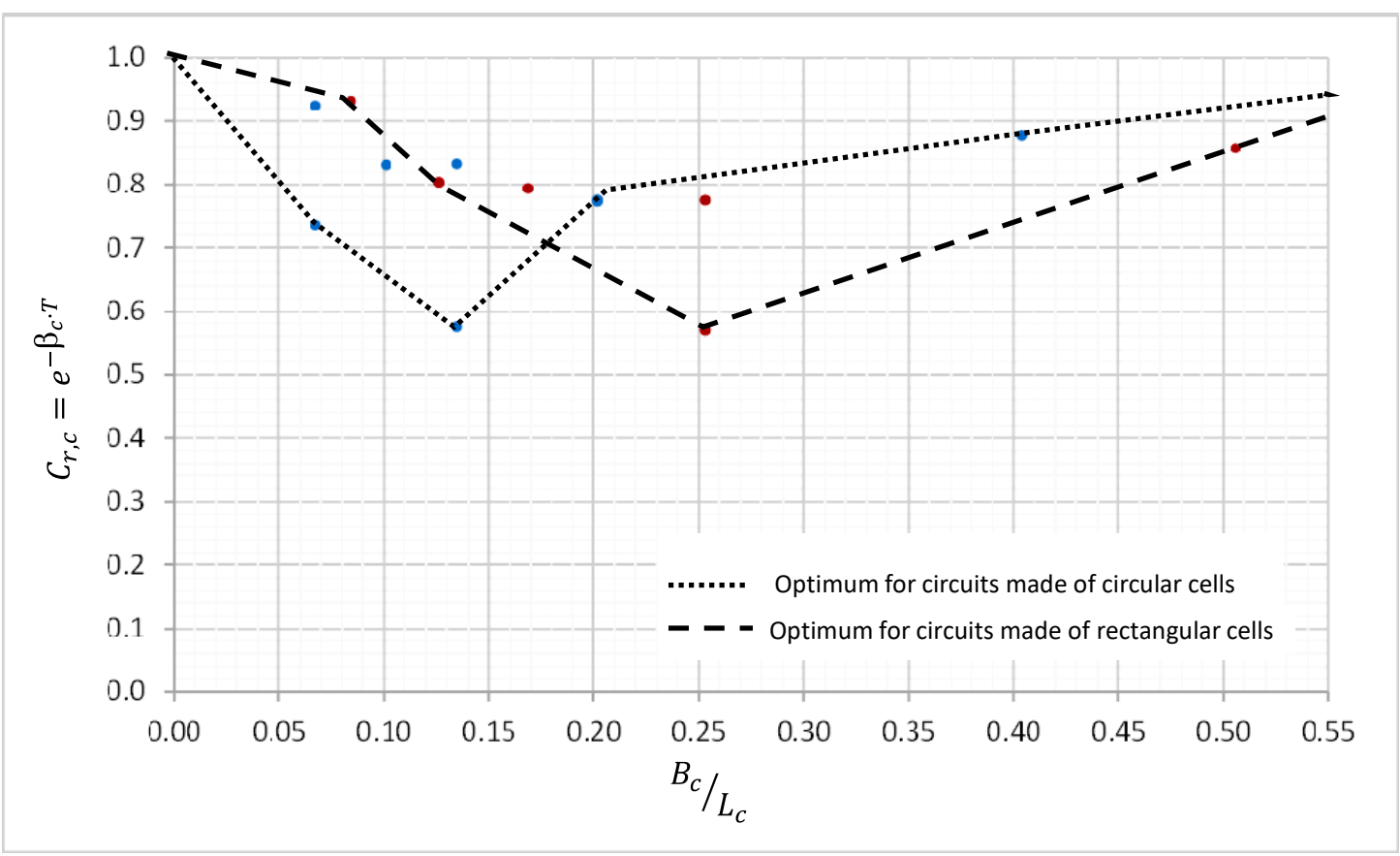

Figure 8. Design diagram for optimizing the length of a dissipative long-circuit. $\left(C_{r, c}=\right.$ circuit reflection coefficient; $B_{c}=$ circuit length; $L_{c}=$ wave length in the circuit)

\section{SUMMARY AND CONCLUSIONS}

Port resonance is a complex problem associated to relevant economic and security issues (increasing port operation downtime and damage to mooring lines, ships and even flooding in the surrounding area).

An extended Jarlan-type structure with dissipative long-circuits (ARJ-R) to reduce long-period oscillation energy has been studied through large scale model tests using a specific experimental Resonant Response Simulation (RRS) methodology to minimize both model and scale effects.

Moreover, the results of the RSS experimentation are analyzed through a complementary procedure based on exponential functions to estimate the reflection coefficient of the ARJ-R caissons tested. The exponential decay procedure allow for a stand-alone characterization of the ARJ-R caisson eliminating other dissipative sources for a more accurate assessment of its dissipative efficiency.

Finally, results of the application of the RRS experimental methodology to large-scale model tests of antireflective structures to reduce resonance in harbors are presented in a diagram for dissipative long-circuit design.

\section{ACKNOWLEDGMENTS}

The authors acknowledge financial support from the Ministerio de Fomento under grant CADIMA P11/08 and the Ministerio de Economía y Competitividad and from the Fondo Europeo de Desarrollo Regional (FEDER) under grant BIA2015-70436-R and from the Ministerio de Economía $y$ Competitividad and the Fondo Europeo de Desarrollo Regional (FEDER) under grant BIA201570436-R. The authors thank Debra Westall for revising the paper.

\section{REFERENCES}

Gonzalez-Escriva, J.A., Medina, J.R., 2012. Antireflective vertical structure extended for attenuation of low frequency waves, Proceedings of the Coastal Engineering Conference, 33 (1). 9 pp. Available at: http://journals.tdl.org /icce/index.php/icce/article/view/6731/pdf [Accessed 17 Nov. 2017].

Gonzalez-Escriva, J.A., 2017. Análisis de la efectividad de las estructuras antirreflejantes en la atenuación de la resonancia en puertos. $\mathrm{PhD}$ Thesis. Universitat Politècnica de València. $357 \mathrm{p}$.

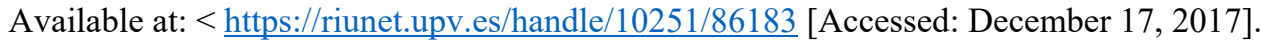


Gonzalez-Escriva, J.A. and Medina, J.R. 2012. Antireflective vertical structure extended for attenuation of low frequency waves. Proceedings of the Coastal Engineering Conference, ASCE, n. 33, pp. structures. 49 .

Gonzalez-Escriva, J.A. 2017. Análisis de la efectividad de las estructuras antirreflejantes en la atenuación de la resonancia en puertos. (in Spanish). PhD Thesis. Universitat Politècnica de València, $357 \mathrm{p}$.

Gonzalez-Escriva, J.A., Gómez-Martín, M.E., Medina, J.R. and Garrido, J.M. 2018. Resonant response simulation methodology for antirrelfective low frequency testing, Proceedings of the CoastLab18 Conference, n. 7 (in press).

Jarlan, G.E. 1961. A perforated vertical breakwater. The Dock and Harbour Authority, FOSLOW, Vol.41 n486, pp. 394-398.

Martinez, S., Manuel, J., Yagüe, D., Garrido, J.M., Ponce de Leon, D., Berruguete, A., GonzalezEscriva, J.A. and Medina, J.R. 2010. Designing a New Low-Reflexivity Quay Wall Caisson, Proceedings of the. $32^{\text {nd }}$ PIANC Conference, pp. 949-963.

Medina, J.R., Gonzalez-Escriva, J.A., Fort, L., Martínez, S., Ponce de León, D., Manuel, J., Yagüe, D., Garrido, J.M, and Berruguete, A. 2016. Vertical Maritime Structure with Multiple Chambers for Attenuation of Wave Reflection, EP 2504496 (B1). European Patent Office, Bulletin 2016 / 26, 29.06.2016.

Rabinovich, A.B. 2009. Seiches and harbor oscillations. Handbook of coastal and ocean engineering, Y.C. Kim ed., World Scientific, pp. 193-236.

Thotagamuwage, D.T. and Pattiaratchi, C. 2014. Observations of infragravity period oscillations in a small marina, Ocean Engineering, Elsevier, vol. 88, pp. 435-445. 